\title{
Designing a Comprehensive Skill Evaluation and Vocational Ability Development Program for FTTH Installer
}

\author{
Takuo Kikuchi \\ Information and Communication Engineering Unit, Polytechnic University, Tokyo 187-0035, Japan
}

\begin{abstract}
Recently, FTTH (fiber to the home) is spreading rapidly, and communication technology has become an indispensable part in our lives. FTTH installers who build the infrastructure must correspond to the progress of technology while ensuring a high quality of installation, and it is struggling to its counterpart. The present study is undertaken in order to propose effective vocational ability development program for FTTH installers from the approach of their skill. They are information network cabling-related qualification system and competitions as the ability evaluation system. Then the author concludes that this program makes a contribution to improving their skill and maintaining the quality of the optical fiber network in analyzing some example of actual installation work and the measurement result of the OTDR(optical time domain reflect) meter.
\end{abstract}

Key words: Vocational ability, development program, FTTH installer, installation skill, evaluation system.

\section{Introduction}

For the rapid spread in broadband network service, the importance of cabling in buildings or in a data centers is increasing. For instance, servers which are the pivot of the service, switches and routers which constitute a network connecting servers, and generic cabling system which connects all those are accumulated in data centers. A person building this infrastructure is a installer of telecommunications technology, especially the FTTH (fiber to the home) installer in this paper can be defined as installer who works near the customer's area. It is known that the quality of cabling installed by installers has a big influence on the whole network and it depends on the skill of the FTTH installers [1]. At the same time, it has been thought that anyone can do these installations such as LAN (local area network) cabling and that it is simple. But with the speed up of telecommunication method, the image changed

Corresponding author: Takuo Kikuchi, Ph.D., assistant professor, research fields: telecommunications, vocational ability development. E-mail: kikuchi@uitec.ac.jp. completely and now cabling is known as a very high technical area. In this case, because many concerns regarding qualities of installation had risen, installers had to prove their skill of FTTH installation. However, the problem seems to lie in the fact that the vocational training for installers was not developed in a systematic manner and little study has been done to the method of the training [2]. On the other hand, the importance of continuous vocational training, CPD (continuing professional development) and its recognition is increasing. The IEEE (institute of electrical and electronics engineers) [3] tries for "Professional Engineer" and environmental maintenance for maintenance of the qualification. In Japan, there is the professional engineer system that is the ability authorization of the engineer [4]. In addition, BICSI (building industry consulting service international) [5] arranges various training and qualification systems and contributes about personnel training. However, as far as we know, there have only been few reports about vocational ability development program for installer's skill, although it is very 
important to discuss about the relation between installer's skill and the quality of network.

The present study was undertaken in order to propose effective vocational ability development program for FTTH installers from the approach of their skill. The paper is organized as follows: section 2 describes the present situation in the FTTH installation industry, moreover the present system and its problems of vocational training for them will be clarified, and the point of the training will be observed; Section 3 explains the situation of FTTH installer's skill; Section 4 discusses on how the vocational ability development program for FTTH installer we proposed was established as well as the effects; Section 5 gives conclusion.

\section{Situation of Vocational Ability Development}

\subsection{FTTH Installation Industry}

FTTH is defined as an access network architecture in which the final connection to the subscriber's premises is optical fiber as in Fig. 1. The optical fiber cable is terminated on or inside the premises boundary for the purpose of carrying communication services to a single subscriber [6].

The optical fiber cable as the access line is installed through various courses, and connection or assembling of optical closure is carried out in the facilities underground. In addition, installers need to install customer's facility such as a media converter in the apartment or in the office buildings. Besides this, installers must perform network setting or the setup of the PC in the customer's house. In general, the FTTH installation industry is labor-incentive type, which is a special characteristic of the construction industry [7]. The network cabling industry has been growing and changing recently. Housing and building constructions have become highly functional and sophisticated with the cutting-edge intelligent functions. The know-how of the integrated management system of disaster prevention and security is also required. Addition to this, in the FTTH installation industry the know-how which you assumed that it was the latest may be completely different in a few years' time. Therefore, the installers must always obtain the latest know-how and put it into practice. Of course as long as the customers have the non-latest systems, for example copper cabling systems of telephone or LAN, they need to maintain their instruments over long periods. In this respect, it should be mentioned that the sphere of activity extend more and more.

\subsection{Carrier Path of FTTH Installer}

This section describes the present conditions of the vocational training of the information network cabling of each country based on the survey among 8 counties which was participating in the WSC (world skills competition) [8]. The WSC explains in detail in Section 4.

The international spread of information networks varies among the countries; some countries have well-developed network environment while the others are currently building infrastructures. While information networks rapidly infiltrate into our lives, every nation faces the problem of shortage of information network cabling professionals. We commonly recognize the importance of improvement in vocational education and training. Because the installation skill of optical fiber is one of the most technical works, it requires a long-term training in order to acquire it.

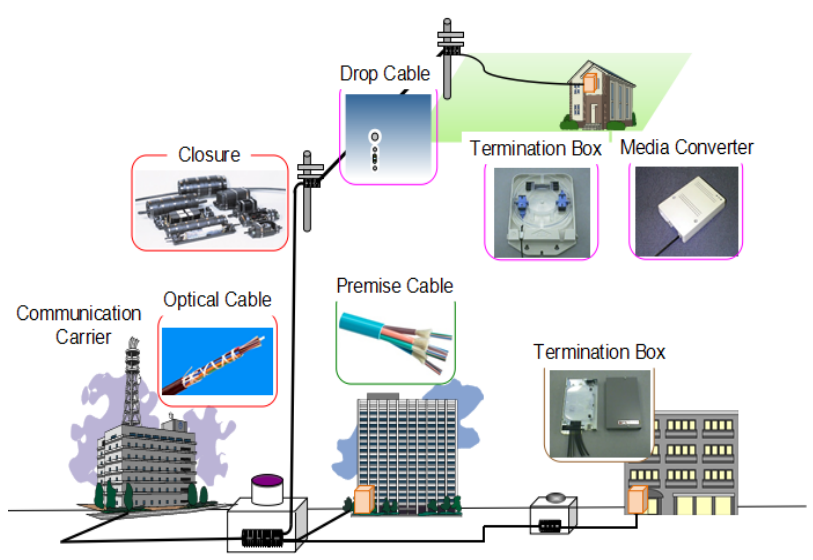

Fig. 1 Access network for FTTH. 
Fig. 2 explains an example of a carrier path in network cabling installation.

The career of installer starts from Level 1, which the basic trainees improve their skills by preparing for operations and helping simple tasks. At the beginning they will be given instructions on how to work, however once they have acquired basic skills, they then learn difficult installation skills. Then they will move up to Level 2 where they are in charge of their own tasks. These workers with a leadership quality will be assisting the section leader or the installer. Usually it takes more than five years of vocational training to reach this level. Next, they advance from Level 2, where they have been recognized as professionals, to Level 3. They have two options: to become a managerial post of foreman who manages the whole working groups, or to become a senior installer who manages his own tasks as well as the others and perform difficult tasks efficiently while maintaining teamwork. They need around ten years of experience to reach this level. In addition, a foreman is expected to learn leadership and management skills, then move to Level 4 and become a senior foreman who has both skills and construction management. It is said to require more than fifteen years of experience to reach from a senior installation technician of Level 3 to become a model of the FTTH installer of Level 4, who is able to perform excellent skills that are demanded by the customers. Also, there are many cases in which the technicians pursue further vocational training after acquiring skills for electric work in order to gain skills for the FTTH installation skill. Therefore, they need to spend double the period of time on further vocational trainings compared to the period of time which they have spent to acquire the skills needed for electric work as shown in Fig. 3.

\section{State of FTTH Installer}

In the previous section, we discussed the duty range of the FTTH installer and the problems in the vocational training. This section explains how the vocational training of the installer is important.

Generally, the installer of optical fiber network is a high skill and needs a long period of training. When this is insufficient, what kind of disadvantage in the network happens? For easier understanding, Fig. 4 shows some pictures that were taken were installed by experienced installer in the field. Notice that the networks of these pictures are connected, although there are some big defects. What kinds of disadvantages these defective works will cause for a customer (in the near future)? Fig. 4 (a); (b) shows the inside of an optical fiber tray and optical enclosure. It is clear from Fig. 4 (a) that bending radius of fibers is small under the regulation and pinching fibers. The small radius raise I L, which is "Insertion Loss" and the pinching may cause break of the fiber. The twist of

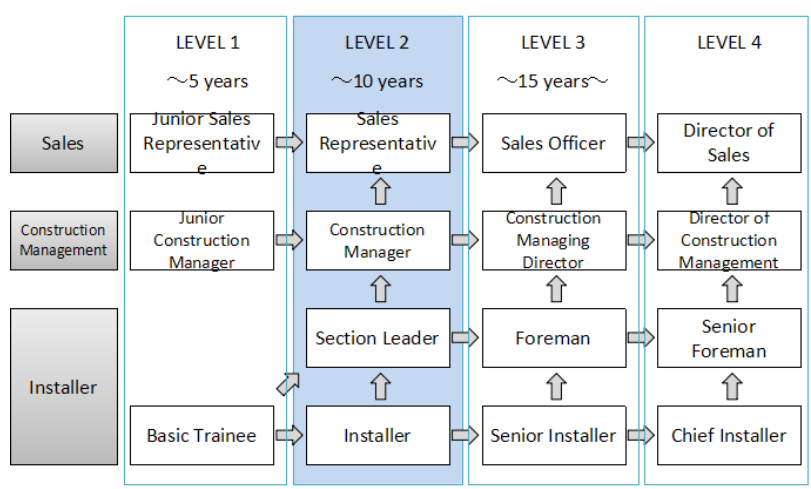

Fig. 2 An example of career map and curriculum of FTTH installer.

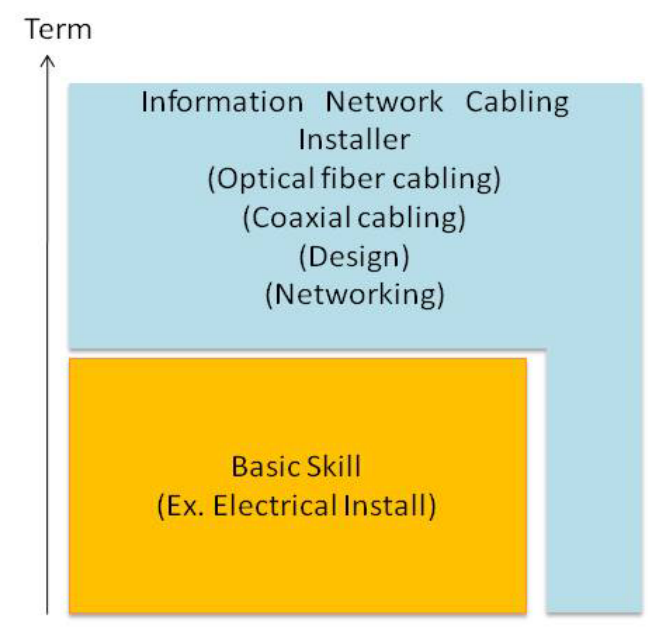

Fig. 3 An example of skills which are ideal for network cabling installation. 


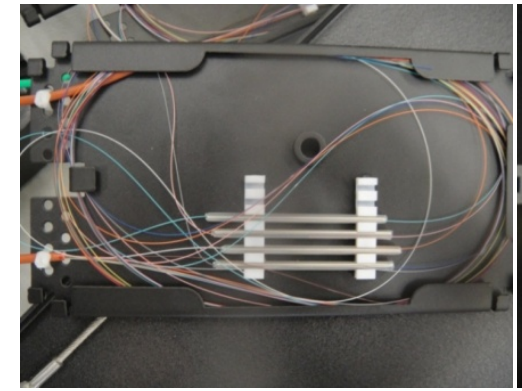

(a) Optical fiber tray

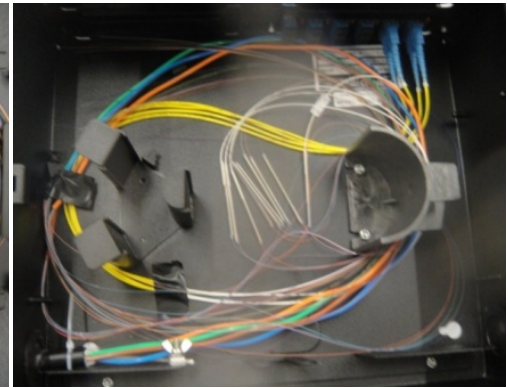

(b) Optical enclosure

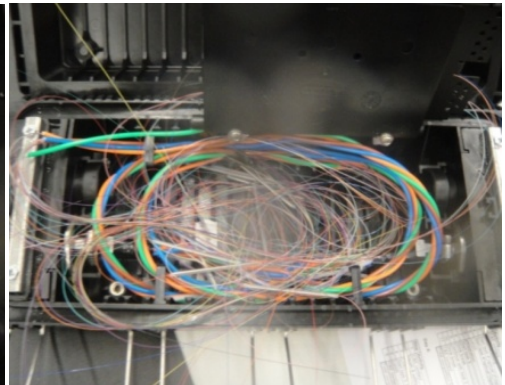

(c) Optical closure.

Fig. 4 Examples of defective working.

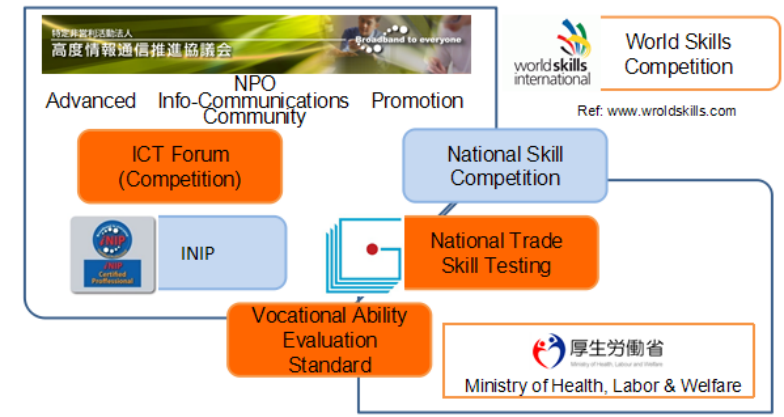

Fig. 5 Overview of our activities.

fiber exists in Fig. 4 (b). The twist will cause the big IL and break of fiber as well. Fig. 4 (c) shows the inside of an underground closure. Regardless to say, it is a very poor installation.

These poor installations are attributed that the installer did not has adequate vocational ability development program. If the installation skill is poor, then it takes extra time for installation and the cost will increase. Moreover, if the installation quality is bad, there will be a possibility that there will be a big influence to the performance of the network, and also when trouble occurs then an enormous time and cost will arise for troubleshooting. More attention should be paid to the fact that it is very important to improve the skill of the installer to secure the quality of the fiber network.

\section{Designing of FTTH Vocational Ability Development Program}

For solving the mentioned problems in previous section, this section presents a new development training system that we proposed in Japan [9-12].

\subsection{Overview of the Program}

Fig. 5 shows the overview of these initiatives we're doing in Japan.

There are two kinds of the skill ability evaluation. One is NTST (national skill trade testing) and the other is VAES (vocational ability evaluation standard). In addition, there is INIP (Information Network Installation Professional) certification that served as an authorized system and training system. Moreover, the three kinds of competition to evaluate installer's skill are ICT (information communication technology) forum, NSC (national skill competition) and WSC. These sponsorship organizations are different each. For INIP and ICT forum, the host organization is a NPO (non-profit organization). The member of NPO is a lot of companies, industrial groups, and schools related to telecommunication industry. Ministry of Welfare, Labor and Health sponsors National Skill competition, NTST, and Vocational Ability Evaluation Standard, and NPO cooperate with them. "World skills international" sponsors the World Skills Competition.

\subsection{Evaluation System for FTTH Installer}

One of the methods to evaluate the skill of the installers includes a qualification system. The system needs some sort of pass standard, it is clear that the training to learn a skill to satisfy the standard is effective for the skill improvement of the installer.

This section explains the evaluation system for installer that we have established the two assessment 
examinations since 2004 in Fig. 6. One of certification is INIP, and the other is NTST. They each have characteristics but they both target on FTTH installers.

\subsubsection{Vendor-Neutral Certification}

The characteristics of INIP certification are 1) vendor-neutral test, 2) testing practical capabilities for "one-stop installation" and 3) a vocational training program. This certification is inferior to other certification in that it is linked to other various certifications or training programs, it makes the best use of installer's resume. The one of example is that the systematized training program is for an installer and is shown in Fig. 7.

Lets us explain the "one-stop installation method" briefly. The "one-stop installation method" which we proposed is a very effective method that the same person or the same supplier install compositely without dividing FTTH installation tasks into specialized workers normally .Considering this, we need various vocational training to switch from a single ability mechanic to a versatile worker.

The goal of installer that is certified by INIP is established in each class. For example, the target of "INIP-Gold" of the highest grade as follows: the certified installer is able to suggest, consult and provide a service technology for the telecommunication network in the home and campus area by one-stop through the communication with the customer.

The range of the authorized standard extends to a wireless technology, LAN installation, the setup of the PC as well as a wiring technology widely. The authorized standard is revised by the committee consisting of such as representative of industrial group and people of learning and experience every year and is shown on the NPO's website. The number of certified installer will increases explosively because of supporting industrial groups and suppliers and starting the authorized school system for educational schools or the suppliers.

\subsubsection{National Trade Skill Testing}

The trade of NTST that Ministry of Health, Labor and Welfare sponsors consists of 128 trades [13], the trade which was established is INC (information network cabling) test. This test can be useful to proof one's vocational ability and can inflect for installation quality proof.

Fig. 8 (a); (b) shows that the range of test and (b) the summary of the INC tests. Each grade has different testing time, qualification of test, percentage for passing, and task. The tests consist of practical and theoretical examinations with three grades. The test is not regarding theoretical stuff but it is regarding installation skill installers should know so the test can

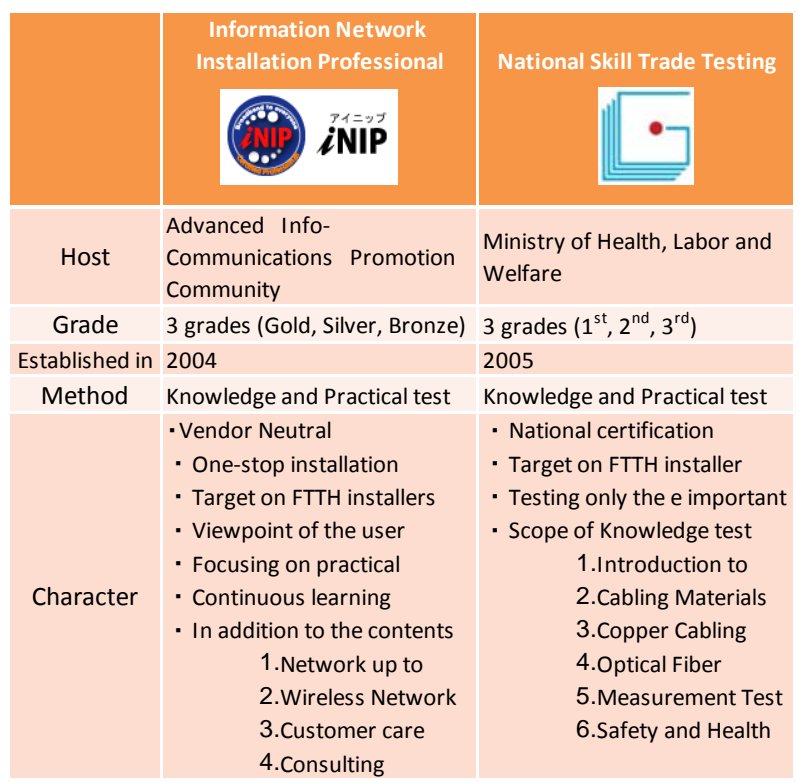

Fig. 6 Overview of evaluation system.

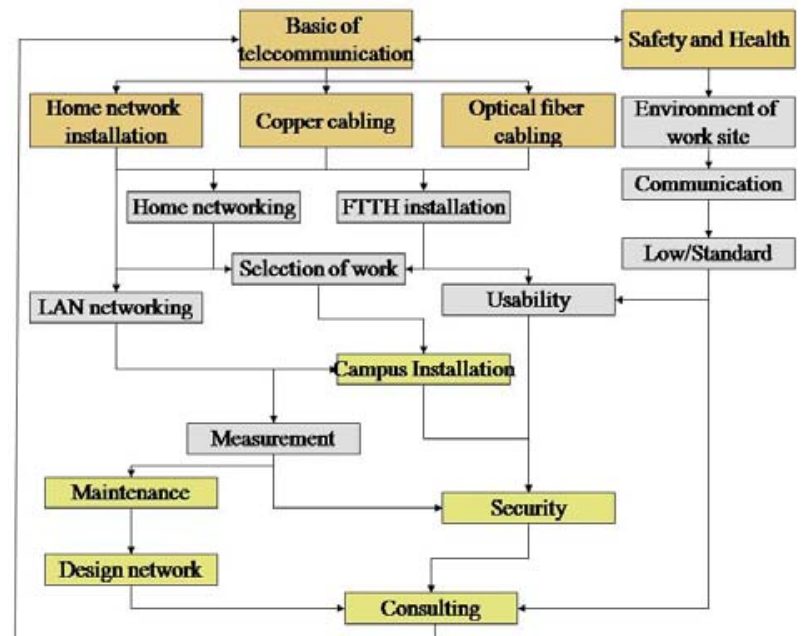

Fig. 7 Example of systematized INIP training program. 


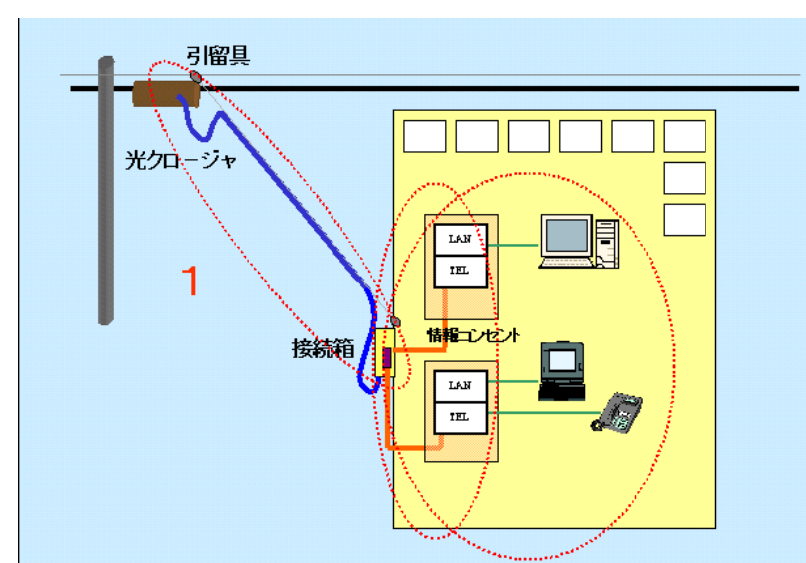

(a) Range of test

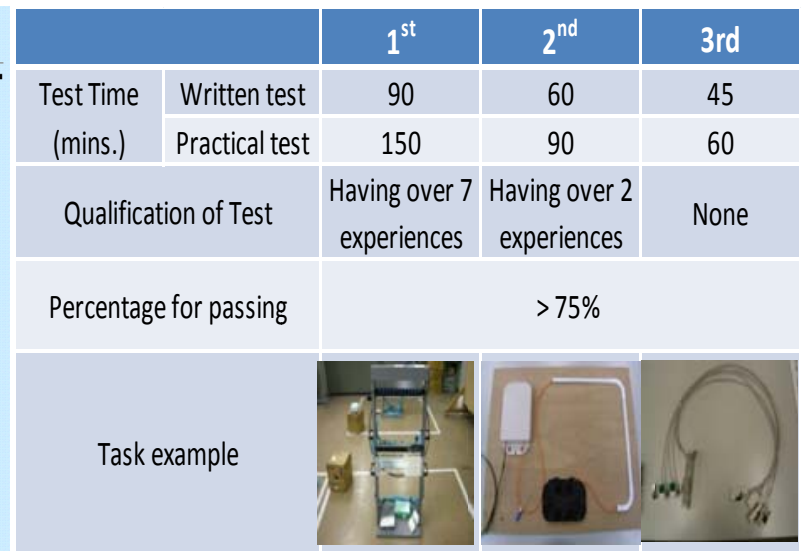

(b) Summary of the INC test

Fig. 8 Summary of the "Information Network Cabling" trade of NTST.

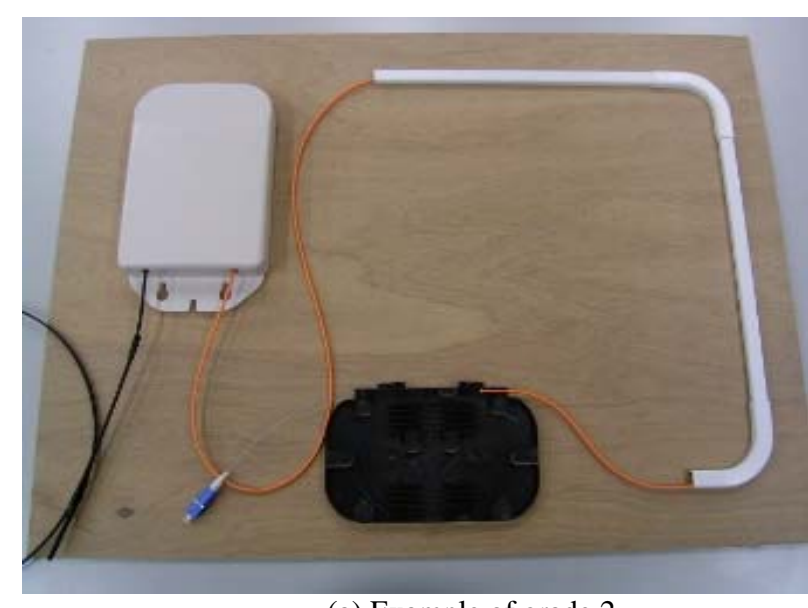

(a) Example of grade 2

Fig. 9 Practical examination of NTST.

be applied in the actual field. Fig. 9 shows an example of the practical examination of grade 2. It is a work to install the optical fiber cable without any twists which is a very basic operation.

The assessor of this test is people who are certified by the minister of Health, Labor, and Welfare. The passer of the test can call himself or herself a certified information network cabling installer.

It is the only national qualification system of the telecommunication's skill in Japan and this examination is utilized as a qualification to publicize a skill level.

\subsubsection{Vocational Ability Evaluation Standard}

We need an ability evaluation standard for the certification. The ministry of Health, Labor and Welfare made vocational skill evaluation criteria in

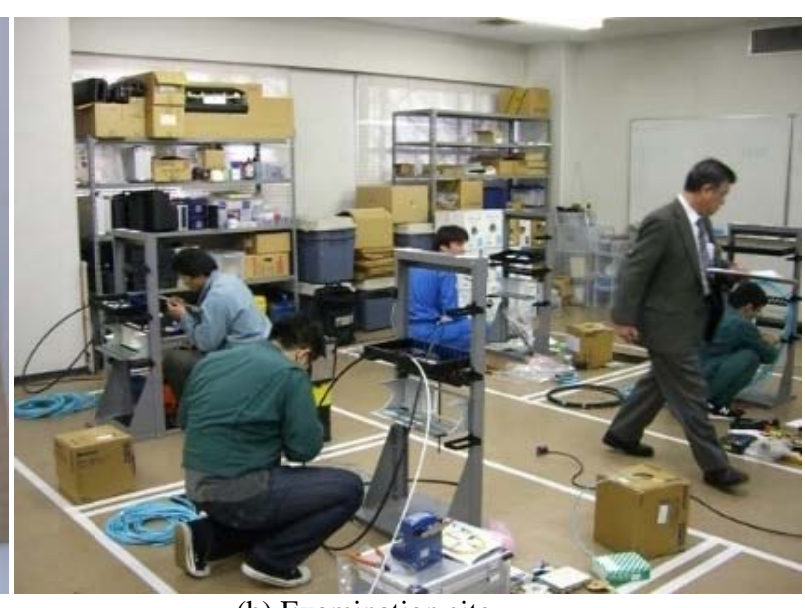

(b) Examination site

2008. The goal is to have the examination become a common measure between installers and industry. We extracted all the work and created evaluation criteria by hearing some typical installation companies and industrial organization. We have also set in stages and in systematic criteria for each level of the installer.

\subsection{Competition}

This section clarifies the effectiveness that can be seen in the vocational training utilizing the competition. Various competitions are held recently, but there was nothing when we started these activities 10 years ago. Fig. 10 shows four main competitions that we are participating or sponsoring [14, 15]. Japanese young people who are under 23 years compete in a national skill competition, which is the 
domestic competition that is served as a primary of WSC. In addition, ICT forum is a competition without age limit in Japan. There is also Cabling Skills Challenge which BICSI sponsors and Japanese representatives have been participating from 2011. The most typical competition, which is WSC is explained in the next section.

\subsubsection{World Skills Competition}

World Skills Competition is a skills competition for young people, which is held every two years. Currently, 69 countries and regions are participating, and there are 46 trades to be competed. The trade in this study is called "Information Network Cabling", the author is a chief expert and one of proposers. So far, Japanese competitor has won 5 competitions consecutively from Finland competition of 2005 to 2013 Leipzig in a trade of "Information Network Cabling”. Next competition will be held in Brazil in 2015.

Competitors challenge to install a given test project 22 hours in the four-day competition. As for the test project of WSC, the current installer's work is reflected and based on the concept of "one-stop installation" in Fig. 11. There are five tasks: 1) Optical fiber cabling; 2) Structured cabling system; 3) Home and office network cabling; 4) Speed test; 5) Trouble-shooting.

Here, let's introduce with one task as an example to show how the competitor's skill is superior.

Task 4, which is a speed test, is a task to fusion splice as many as possible in 45 minutes. The installers specializing in fusion splice in the actual

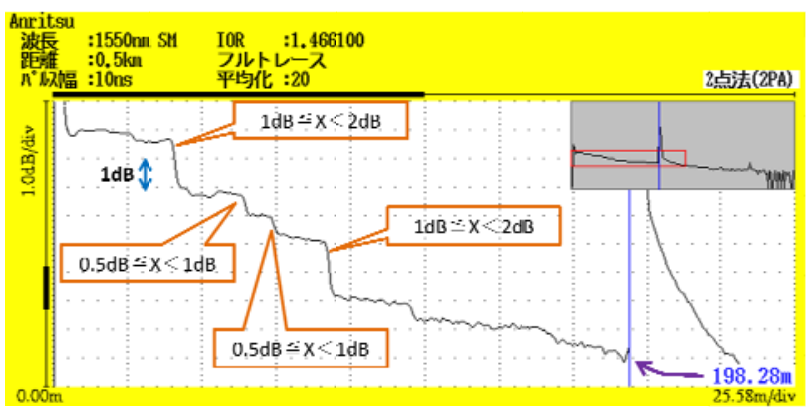

(a) Result of a general installer field were able to connect only around 20 of them, but on the other hand, the champion in WSC2013 connected 85 of them. It is a noteworthy fact that the each splices loss should below as well as the speed. Fig. 12 (a) shows a result of a general installer by OTDR (Anritsu, MT-9083 Access master), and Fig. 12 (b) is a perfect result of a competitor of National Skills Competition. As the OTDR trace indicates, the loss value of the competitor's splicing was low in all

\begin{tabular}{|c|c|c|c|c|}
\hline rost & $\begin{array}{l}\text { Worc SkIs } \\
\text { neta mational }\end{array}$ & $\begin{array}{l}\text { Mristry of } \\
\text { Labour, ream } \\
\text { and We fare }\end{array}$ & $\begin{array}{c}\text { Aovanced into } \\
\text { Communcations } \\
\text { Promotion } \\
\text { Communtly }\end{array}$ & BCs \\
\hline Name & $\begin{array}{l}\text { World Skis } \\
\text { Compettion }\end{array}$ & $\begin{array}{l}\text { Natonal Skills } \\
\text { compettion }\end{array}$ & ICT Forum & $\begin{array}{l}\text { Cabing } \\
\text { Chalenge }\end{array}$ \\
\hline Establaned & $\begin{array}{l}2005 \\
\left(\begin{array}{l}\text { every } 2 \\
\text { years) }\end{array}\right.\end{array}$ & $\begin{array}{c}2004 \\
\text { (onoe a year) }\end{array}$ & $\begin{array}{c}2004 \\
\text { (once a year) }\end{array}$ & $\begin{array}{c}2008 \\
\text { (once a year? }\end{array}$ \\
\hline \multirow{2}{*}{$\begin{array}{l}\text { Particlpating } \\
\text { Countries }\end{array}$} & \multirow{2}{*}{18 countres } & Japan & Japan & \multirow{2}{*}{$\begin{array}{l}\text { US. A. Japan, } \\
\text { Oeners. }\end{array}$} \\
\hline & & (24 osmpettors) & (35 compentors) & \\
\hline Age Lmts & Under 25 & Under 24 & None & $\begin{array}{l}\text { Ex perlence } \\
\text { over } 10 \text { years }\end{array}$ \\
\hline
\end{tabular}

Fig. 10 Summary of competitions.

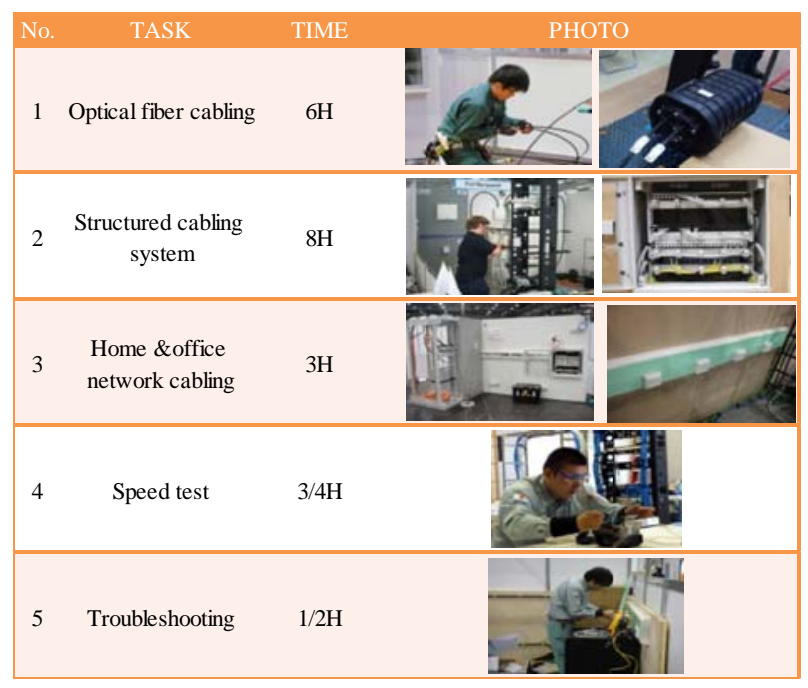

Fig. 11 Test projects.

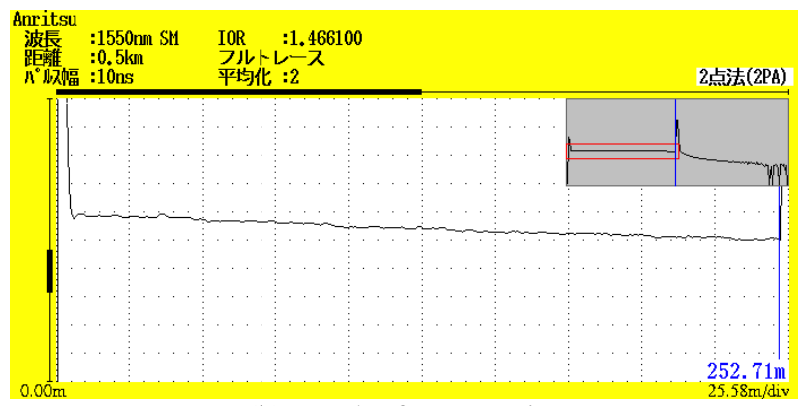

(b) Result of a competitor

Fig. 12 Comparison of connection loss using an OTDR (optical time domain reflect) meter. 
connections, while the installer's splicing was high.

From this result, it shows that a fully trained installer can bring the development of the speed and quality of installation.

In this way, it can be said that the systematized training utilizing a competition that we proposed has the advantage that their skill of installers and the quality of installation improve effectively. It should also be noted that this method could improve working efficiency at an installation site by shortening the installation period.

\subsubsection{Effect of the Competition}

The participating competition is helpful in developing their skill for the field installers. The first thing to be noticed is that they can get a chance to have their own skill evaluated objectively. It will be good for development and improvement to have your own skill evaluated using the evaluation standard mentioned above. In addition, viewing the skill of other installers is useful to self-evaluate.

The other point is that the training for the competition brings the establishment of the instruction method. By looking at the result of Japan winning the competition continuously, the effect of the established instruction method is clear. Competitors might have less experience in the actual field, but have a tremendous skill. In Japan, we cannot find any installer who can compete with World Skills competitor. Even an experienced installer cannot beat them. The reason is because the competitors are fully trained. This means that this training system will be applied to not only World Skills competitors, but to all installers of the field, and this will produce many installers of talent. Because the effective instruction method is established for training competitors, many trained installers in the industrial field will be produced. In other words, installers of the whole industrial field could improve and develop their skill by using this method in training facilities.

Besides the things mentioned above, participating in WSC has other effect. The installation standard can be seen easily. For example, a collection of best practice of WSC has used in our program in Fig. 13. From training point of view, it is very effective.

Moreover, there will be a vocational ability development in accordance with the international standard by adopting the marking standard of the competition to each country's marking standard.

\subsection{Mutual Cooperation}

We would like to emphasize that these evaluation system; INIP certification, NTST, and World Skills Competition cooperate mutually in using the same assessment criteria. For example, the second grade acquisition of the Skill Test is necessary to participate in the World Skills Competition. And the high achiever in the World Skills Competition will be given a first grade qualification of the Skill Test. Furthermore, an evaluation standard of the National Skills Competition and the Skill Test are connected with WSC and each and can bring up installers systematically.

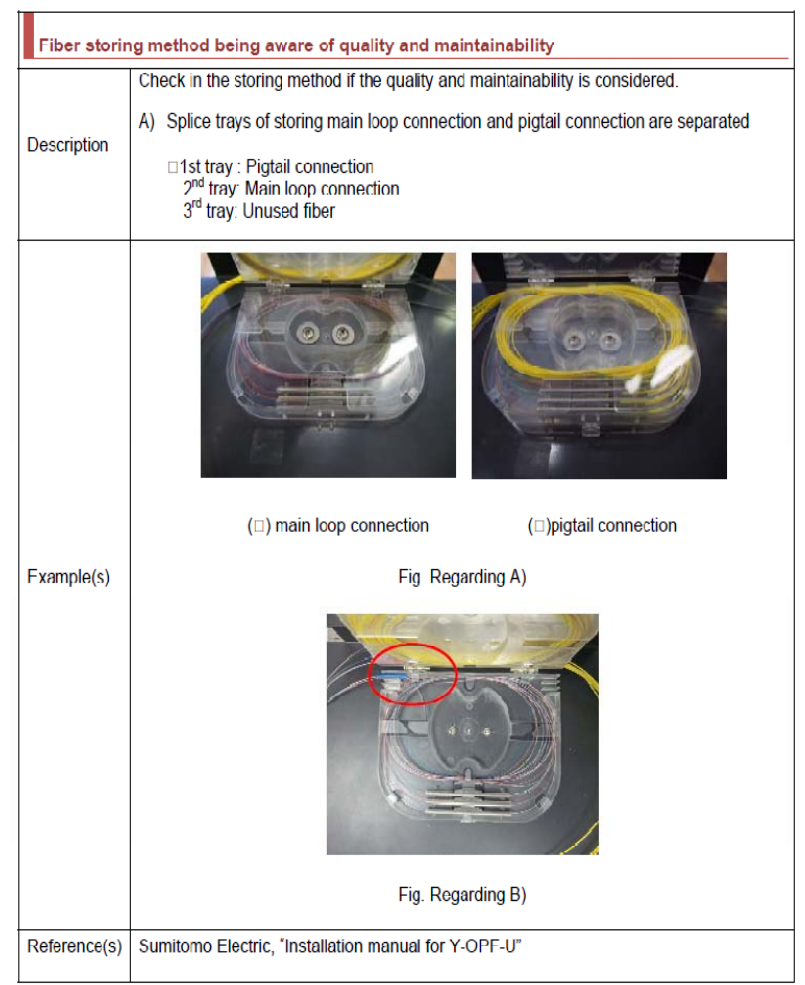

Fig. 13 One example of "best practice" collection. 


\section{Conclusion}

The foregoing discussion has described the improper installations in the FTTH field was caused by poor skill of installer or inadequate vocational training. Moreover, the vocational ability development program that we proposed was explained, such as INIP certification, National Trade Skill Testing and some competitions. They are information network cabling-related qualification system and competitions as the ability evaluation system. Then the measurement result of optical loss by using the OTDR indicates that the trained installer has high level skill. In conclusion, this program has been shown very effective for improving their skill and maintaining the quality of the network. It is critical that the many installers can improve and develop their skill by using this program effectively in training facilities.

In addition, by creating a system to train and evaluate the installers, the system will be able to provide greater rewarding for the installers. Thus more attention will be paid to the importance of the installer's skill if this evaluation system gets recognized more. For the result, the installation quality will also improve.

We have also carried these activities out not only in Japan but also in the ASEAN (Association of South East Asian Nations) countries. Moreover, by using this instruction method, we have supported vocational training in ten countries since 2008.

It is hoped that the outcome of the present study and our activities would be of some use to develop the installer's skill and provide a comfortable optical fiber network environment to the customer.

\section{Acknowledgement}

The continued support of the member of advanced Info-Communications Promotion Community and the medalists and instructors of World Skills Competition are greatly appreciated.

\section{References}

[1] Fluke Networks. 2013. Accessed June 10, 2013. http://www.flukenetworks.com/knowledge-base.

[2] Sugita, D., and Takuo K. 2014. "A Method of an Efficient Installation Process for Generic Cabling inside Customer Premises.” In proceedings of 1st International Conference on Intelligent Green Building and Smart Grid, 214-5.

[3] Institute of Electrical and Electronics Engineers. 2014. "Education and Carrier." Accessed March 14, 2014. http://www.ieee.org/education_careers/education/professi onal_certification/.

[4] The Institution of Professional Engineers Japan. 2014. “Professional Engineer CPD.” Accessed March 10, 2014. http://www.engineer.or.jp/.

[5] BICSI. 2014. "Credential Information.” Accessed March 10, 2014. https://www.bicsi.org/.

[6] Lee, B. 2014. "Key Challenges and Obstacles to FTTH Deployments in Asia-Pacific.” Presented at Asia-Pacific Conference 2014, Penang, Malaysia.

[7] Japan Vocational Ability Development Association. 2007. Comprehensive Vocational Ability Development System Committee-Telecommunication Installation Industry - In Japanese). Report. JAVADA.

[8] World Skills International. 2014. "Skills Competition." Accessed April 11, 2014. http://www.worldskills.com/.

[9] Takuo K. 2014. "Designing Comprehensive FTTH Training Program throughout Japan and the World." Presented at the Asia-Pacific conference 2014, Jakarta, Indonesia.

[10] Advanced Info-Communication Promotion Committee. 2014. “INIP Exam Information.” Accessed December 25, 2010. http://www.b2every1.org.

[11] Takuo Kikuchi. 2003. "Consideration about the Vocational Training in the Field of the Information Network Cabling (in Japanese)." In Proceedings of Practical Technology and Education 2003, 34-5.

[12] Advanced Info-Communication Promotion Committee. 2014. “Ginou Kentei Information.” Accessed September 5, 2010. http://www.b2every1.org/kentei.

[13] Ministry of Health, Labor and Welfare. 2014. "Vocational Ability Development.” Accessed April 2, 2014. http://www.mhlw.go.jp/.

[14] Japan Vocational Ability Development Association. 2014. “National Skills Competition.” Accessed March 9, 2014. http://www.javada.or.jp/jigyou/gino/zenkoku/.

[15] BICSI Cabling Skills Challenge. 2014. "CSC2014.” Accessed March 5, 2014 https://www.bicsi.org/skillschallenge/. 